\title{
POTENTIAL REFRIGERANTS FOR POWER ELECTRONICS COOLING
}

Prepared by:

Oak Ridge National Laboratory

Mitch Olszewski, Program Manager

Submitted to:

Energy Efficiency and Renewable Energy

FreedomCAR and Vehicle Technologies

Vehicle Systems Team

Susan A. Rogers, Technology Development Manager

October 2005 
NATIONAL LABORATORY

MANAGED BY UT-BATTELLE

FOR THE DEPARTMENT OF ENERGY
Engineering Science and Technology Division

\section{POTENTIAL REFRIGERANTS FOR POWER ELECTRONICS COOLING}

M. R. Starke

The University of Tennessee-Knoxville

C. W. Ayers

J. S. Hsu

J. C. Conklin

Oak Ridge National Laboratory

Publication Date: October 2005

Prepared by the

OAK RIDGE NATIONAL LABORATORY

Oak Ridge, Tennessee 37831

managed by

UT-BATTELLE, LLC

for the

U.S. DEPARTMENT OF ENERGY

Under contract DE-AC05-00OR22725 
This report was prepared as an account of work sponsored by an agency of the United States Government. Neither the United States Government nor any agency thereof, nor any of their employees, makes any warranty, express or implied, or assumes any legal liability or responsibility for the accuracy, completeness, or usefulness of any information, apparatus, product, or process disclosed, or represents that its use would not infringe privately owned rights. Reference herein to any specific commercial product, process, or service by trade name, trademark, manufacturer, or otherwise, does not necessarily constitute or imply its endorsement, recommendation, or favoring by the United States Government or any agency thereof. The views and opinions of authors expressed herein do not necessarily state or reflect those of the United States Government or any agency thereof. 


\section{TABLE CONTENTS}

Page

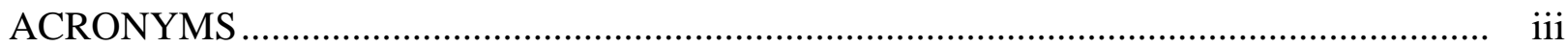

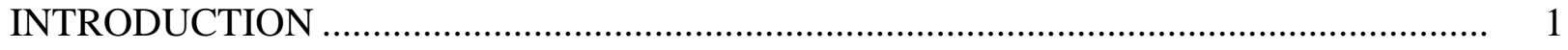

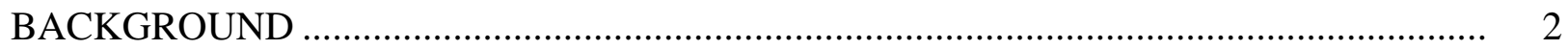

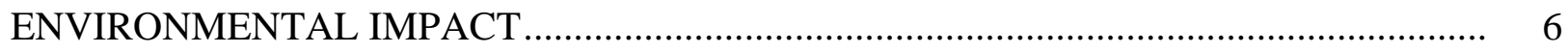

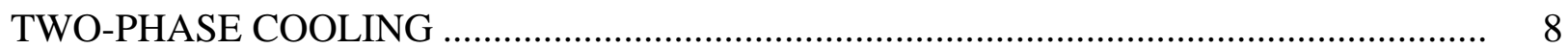

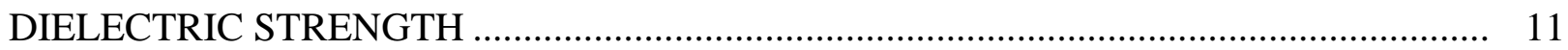

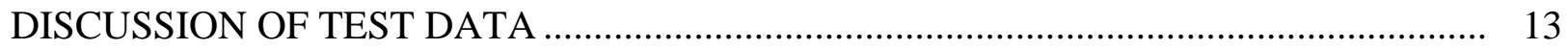

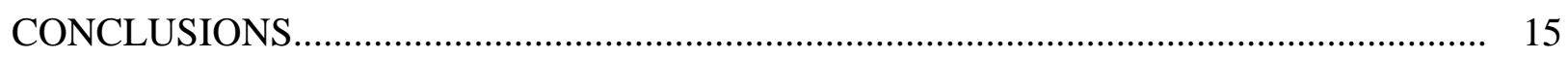

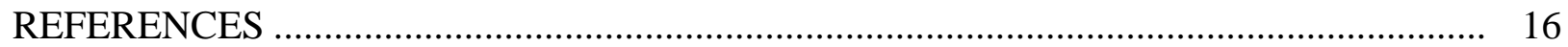

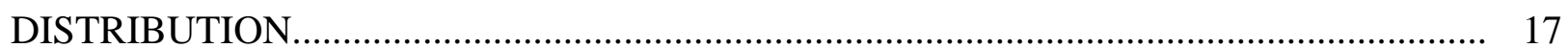

\section{LIST OF FIGURES}

$\begin{array}{lll}\text { Figure } & \text { Page }\end{array}$

$1 \quad$ PEs submerged in a simple refrigerant cooling system ............................................. 4

2 Refrigerant GWP ……………………………............................................... 8

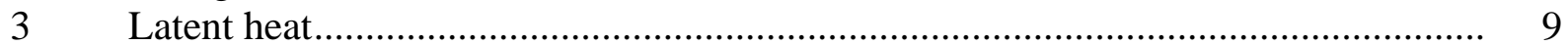

$4 \quad$ Latent heat excluding water ....................................................................... 9

\section{LIST OF TABLES}

$\begin{array}{lll}\text { Table Page } & \text { Pan }\end{array}$

1 List of refrigerants.....................................................................................

2 Environmental, ignitability, and health data .............................................................. 7

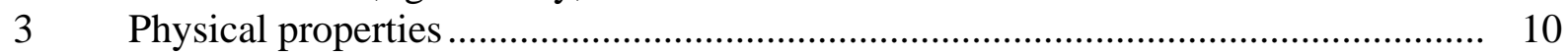

$4 \quad$ Dielectric strength table ................................................................................... 12 


\section{ACRONYMS}

CFC

GWP

$\mathrm{HC}$

chlorofluorocarbon

HCFC

HFC

HFE

ICE

MS

ODP

$\mathrm{PE}$

PFC global-warming potential

hydrocarbons

hydrochlorofluorocarbon

hydrofluorocarbon hydrofluoroether internal combustion engine methylsiloxane ozone-depleting potential power electronic perfluorocarbons 


\section{INTRODUCTION}

In the past, automotive refrigerants have conventionally been used solely for the purpose of air conditioning. However, with the development of hybrid-electric vehicles and the incorporation of power electronics (PEs) into the automobile, automotive refrigerants are taking on a new role.

Unfortunately, PEs have lifetimes and functionalities that are highly dependent on temperature and as a result thermal control plays an important role in the performance of PEs. Typically, PEs are placed in the engine compartment where the internal combustion engine (ICE) already produces substantial heat. Along with the ICE heat, the additional thermal energy produced by PEs themselves forces designers to use different cooling methods to prevent overheating. Generally, heat sinks and separate cooling loops are used to maintain the temperature. Disturbingly, the thermal control system can consume one third of the total volume and may weigh more than the PEs [1]. Hence, other avenues have been sought to cool PEs, including submerging PEs in automobile refrigerants to take advantage of two-phase cooling. The objective of this report is to explore the different automotive refrigerants presently available that could be used for PE cooling. Evaluation of the refrigerants will be done by comparing environmental effects and some thermo-physical properties important to two-phase cooling, specifically measuring the dielectric strengths of potential candidates. Results of this report will be used to assess the different candidates with good potential for future use in PE cooling. 


\section{BACKGROUND}

Cooling PEs in a refrigerant requires that the refrigerant meet certain constraints. First, the refrigerant must be environmentally friendly. The number of automobiles in the world is continually increasing and to prevent environmental damage, refrigerants must be environmentally sound. Second, the refrigerant must be effective at two-phase cooling. This implies that the refrigerant has appropriate thermo-physical properties. Last, the refrigerant must have high-dielectric strength. High-dielectric strength prevents current from traveling through the working fluid and causing damage to or malfunctions in PEs and other components via a short circuit. With these constraints in mind, Table 1 is a potential list of refrigerants for investigation.

Technology and awareness of the environment have forced improvements in automotive refrigerants. Early refrigerants consisted of sulfur dioxide and ammonia, which are both corrosive and toxic. Chlorofluorocarbons (CFCs), a family of non-toxic inert chemicals composed of chlorine, fluorine, and carbon, were developed in the 1930s as a safer alternative to sulfur dioxide and ammonia. Although CFCs are non-toxic, they were discovered to be ozone depleting and were found to add to the global-warming potential (GWP) [2]. To combat the detrimental effects of CFCs, governments around the world met and decided on a course of action known as the Montreal Protocol. The Montreal Protocol, established in 1987, called for the consumption of ozone-depleting compounds to be phased out by 2000, basically eliminating the use of CFCs [3,4]. Hydrochlorofluorocarbons (HCFCs) became the next step in the refrigeration evolution providing similar characteristics to their CFC counterparts but with only $10 \%$ of the ozone-depleting potential (ODP) [5]. Hydrofluorocarbons (HFCs), perfluorocarbons 
(PFCs), hydrofluoroethers (HFEs), and methylsiloxane (MSs) are all recently developed agents providing zero ODP and lower GWP.

Table 1. List of refrigerants

\begin{tabular}{|c|c|c|}
\hline $\begin{array}{l}\text { Cooling fluid } \\
\text { description }\end{array}$ & & \\
\hline & Company & Product name \\
\hline $1,1,1,2$ tetra fluorethane & Various & HFC-134a \\
\hline 1,1-dichloro-1-fluoroethane & Various & HCFC-141b \\
\hline 1-chloro-1,1-difluoroethane & various & HCFC-142b \\
\hline Dichlorodifluoro methane & Various & CFC-12 \\
\hline Chlorodifluoro methane & Various & HCFC-22 \\
\hline perfluorocarbon & $3 \mathrm{M}$ & Fluoroinert FC-87 \\
\hline perfluorocarbon & $3 \mathrm{M}$ & Fluoroinert FC-72 \\
\hline perfluorocarbon & $3 \mathrm{M}$ & Fluoroinert FC-77 \\
\hline hydrofluoroether & $3 \mathrm{M}$ & Novec HFE-7000 \\
\hline hydrofluoroether & $3 \mathrm{M}$ & Novec HFE-7100 \\
\hline hydrofluoroether & $3 \mathrm{M}$ & Novec HFE-7200 \\
\hline methylsiloxane & Dow Corning & Cleaning Agent 1 \\
\hline methylsiloxane $60 \%$ w/alcohol & Dow Corning & Cleaning Agent 2 \\
\hline De-Ionized Water & & $\mathrm{H}_{2} \mathrm{O}$ \\
\hline $\begin{array}{c}\text { hydrocarbon blend } \\
\text { (butane/isobutane/propane) }\end{array}$ & Duracool & Duracool 12a \\
\hline $\begin{array}{l}\text { hydrocarbon blend ( } \\
\text { propane/butane) }\end{array}$ & Enviro-safe & ES-12 \\
\hline $\begin{array}{c}\text { fluorocarbon blend (HFC- } \\
134 a / H C F C-142 b)\end{array}$ & Technical Chemical & Freeze 12 \\
\hline
\end{tabular}

For the refrigerants to be applicable in this study, the refrigerants must be capable of cooling PEs. Cooling through the use of refrigerants can be split into two categories, direct and indirect cooling. Indirect cooling does not permit contact between the refrigerant and PEs, but instead provides a thermal pathway between PEs and the refrigerant. Direct cooling, on the other 
hand, places PEs directly in contact with the refrigerant. Since no separation or thermal resistance exists between the cooling source and PEs, direct cooling provides a much greater overall heat-transfer coefficient and, therefore, is capable of removing larger quantities of heat in a smaller volume. This gives direct cooling a distinct advantage over indirect cooling [6].

With direct cooling, a two-phase cooling approach is customarily used. As the name implies, two-phase cooling uses two phases, liquid and vapor. Due to the heat produced by PEs, a temperature gradient is created and initiates convection [6]. As PEs begin to heat, the refrigerant in contact with PEs eventually boils and converts to vapor as seen in Fig. 1. Through buoyancy, hot vapor rises away from the heat source removing the heat. Once the vapor reaches the ambient cooling (condenser) surface, the vapor begins to cool. Eventually, the vapor returns to the liquid state to complete the cycle.

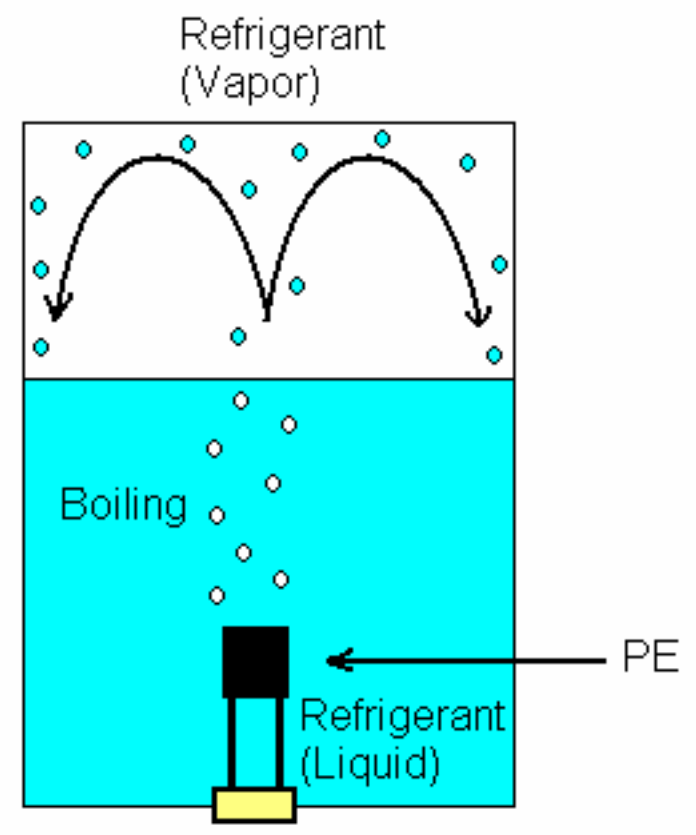

Fig. 1. PEs submerged in a simple refrigerant cooling system.

Depending on the thermo-physical properties of the refrigerant, numerous levels of cooling are obtainable. Latent heat is the amount of heat per unit mass required to convert the 
refrigerant from liquid to vapor phase. A large value of latent heat signifies that the refrigerant can remove a significant amount of heat with low-boiling action. For cooling PEs submerged in refrigerant, fluids with higher latent-heat values are preferred due to the substantial amount of thermal energy that must be removed from small areas. Refrigerants with lower latent-heat values must flow much more refrigerant, demanding considerably more vapor removal. This additional vapor removal constrains the system to the use of more bulky vapor handling components. Furthermore, large latent-heat values have a potential advantage in increasing the system volumetric power density.

The normal-boiling temperature gives an indication of the pressure that is needed to maintain two phases in the container. Refrigerants with low normal-boiling temperatures necessitate higher pressure to maintain two phases and temperatures appropriate for PE cooling. Conversely, refrigerants with high normal-boiling temperatures need lower, subatmospheric pressure to maintain two phases. A preference is given to a refrigerant that has a normal-boiling point between $20-80^{\circ} \mathrm{C}$ since a medium pressure container would not be required to cool the PEs.

A major issue with submerging PEs in refrigerant is the dielectric strength. Highdielectric strength of a fluid enables it to resist current under high-voltage potential. Since PEs are completely exposed in the refrigerant, the fluid must not permit the flow of current to short circuit and damage the PEs and other components or to cause malfunction of the PE control circuits. 


\section{ENVIRONMENTAL IMPACT}

As previously noted, an important factor in deciding the viability of the refrigerant is the environment. Table 2 depicts data concerning environmental, flammability, and health concerns of the refrigerants under investigation. CFCs have the worst environmental impact with a large ODP and GWP (100 years) and, as previously mentioned, have been eliminated from use through the Montreal Protocol. The only other refrigerants to have ODP are the HCFCs. Although HCFCs have a much lower ODP value, the Copenhagen Amendments to the Montreal Protocol call for the cessation of production of ozone-depleting compounds by 2010 [5], eliminating the use of HCFCs in the future.

Figure 2 graphically represents the GWP of different refrigerants in reducing order. Clearly from Fig. 2, CFCs and PFCs are undesirable refrigerants in terms of the environment with significantly larger GWP values compared to other refrigerants. A noteworthy observation is the low GWP values of HFE, (hydrocarbons) HC, and MS refrigerants. Along with low values

of GWP, these refrigerants have no ODP and low environmental impact. Still, water is the optimum refrigerant with no harmful effects to the environment. 
Table 2. Environmental, ignitability, and health data

\begin{tabular}{|c|c|c|c|c|c|c|c|c|c|}
\hline \multirow[t]{2}{*}{$\begin{array}{l}\text { Cooling Fluid } \\
\text { Description }\end{array}$} & \multirow[b]{2}{*}{ Company } & \multirow[b]{2}{*}{ Product Name } & \multirow{2}{*}{$\begin{array}{c}\text { Flammable? } \\
\text { Yes/No }\end{array}$} & \multirow{2}{*}{$\begin{array}{c}\begin{array}{c}\text { Auto } \\
\text { Ignition }\end{array} \\
\text { Point } \\
\left({ }^{\circ} \mathrm{C}\right)\end{array}$} & \multirow{2}{*}{$\begin{array}{c}\begin{array}{c}\text { Lower Expl. } \\
\text { Limit }\end{array} \\
\text { LEL (\%) }\end{array}$} & \multicolumn{2}{|c|}{ Enviornmental } & \multirow{2}{*}{ 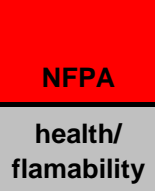 } & \multirow{2}{*}{$\begin{array}{c}\text { HMIS } \\
\begin{array}{c}\text { health/ } \\
\text { flamability }\end{array}\end{array}$} \\
\hline & & & & & & $\begin{array}{c}\text { ODP } \\
\text { (R11=1) }\end{array}$ & $\begin{array}{l}\text { GWP } \\
(100 \mathrm{yr})\end{array}$ & & \\
\hline $1,1,1,2$ tetra fluorethane & Various & HFC-134a & No & 750 & NA & 0 & 1300 & $1 / 0$ & $1 / 0$ \\
\hline $\begin{array}{c}\text { 1,1-dichloro-1- } \\
\text { fluoroethane }\end{array}$ & Various & HCFC-141b & Yes & 325 & 6 & 0.086 & 700 & $1 / 0$ & $1 / 0$ \\
\hline $\begin{array}{c}\text { 1-chloro-1,1- } \\
\text { difluoroethane }\end{array}$ & various & HCFC-142b & Yes & 632 & 9 & 0.043 & 2300 & $1 / 0$ & $1 / 0$ \\
\hline $\begin{array}{l}\text { Dichlorodifluoro } \\
\text { methane }\end{array}$ & Various & CFC-12 & No & $>750$ & NA & 0.82 & 10600 & $2 / 4$ & $2 / 4$ \\
\hline Chlorodifluoro methane & Various & HCFC-22 & No & NA & NA & 0.034 & 1700 & $2 / 1$ & $2 / 1$ \\
\hline perfluorocarbon & $3 \mathrm{M}$ & Fluoroinert FC-87 & No & NA & NA & 0 & 8900 & $3 / 0$ & $0 / 0$ \\
\hline perfluorocarbon & $3 \mathrm{M}$ & Fluoroinert FC-72 & No & NA & NA & 0 & 9000 & $3 / 0$ & $1 / 0$ \\
\hline perfluorocarbon & $3 \mathrm{M}$ & Fluoroinert FC-77 & No & NA & NA & 0 & 9000 & $3 / 0$ & $1 / 0$ \\
\hline hydrofluoroether & $3 \mathrm{M}$ & Novec HFE-7000 & No & 415 & NA & 0 & 400 & $3 / 1$ & $0 / 1$ \\
\hline hydrofluoroether & $3 \mathrm{M}$ & Novec HFE-7100 & No & 405 & NA & 0 & 320 & $3 / 1$ & $0 / 1$ \\
\hline hydrofluoroether & $3 \mathrm{M}$ & Novec HFE-7200 & No & 375 & 2.4 & 0 & 55 & $3 / 0$ & $1 / 0$ \\
\hline methylsiloxane & $\begin{array}{l}\text { Dow } \\
\text { Corning }\end{array}$ & Cleaning Agent 1 & Yes & 341.1 & 1.25 & 0 & $<10$ est & $1 / 3$ & \\
\hline $\begin{array}{c}\text { methylsiloxane } 60 \% \\
\text { w/alcohol }\end{array}$ & $\begin{array}{c}\text { Dow } \\
\text { Corning }\end{array}$ & Cleaning Agent 2 & Yes & 365 & 1.3 & 0 & $<10$ est & $1 / 3$ & \\
\hline De-Ionized Water & & $\mathrm{H}_{2} \mathrm{O}$ & No & NA & NA & 0 & $<1$ est & & \\
\hline $\begin{array}{c}\text { (butane/isobutane/prop } \\
\text { ane) }\end{array}$ & Duracool & Duracool 12a & Yes & 891 & 1.95 & 0 & $\sim 20$ & $1 / 4$ & $1 / 4$ \\
\hline $\begin{array}{c}\text { hydrocarbon blend ( } \\
\text { propane/butane) }\end{array}$ & Enviro-safe & ES-12 & Yes & 863 & 1.9 & 0 & $\sim 20$ & $1 / 4$ & $1 / 4$ \\
\hline $\begin{array}{l}\text { fluorocarbon blend } \\
\text { (HFC-134a/HCFC-142b) }\end{array}$ & $\begin{array}{l}\text { Technical } \\
\text { Chemical }\end{array}$ & Freeze 12 & No & $>150$ & $\begin{array}{c}\text { not } \\
\text { determined }\end{array}$ & 0.01 & 1500 & $2 / 2$ & $2 / 2$ \\
\hline
\end{tabular}




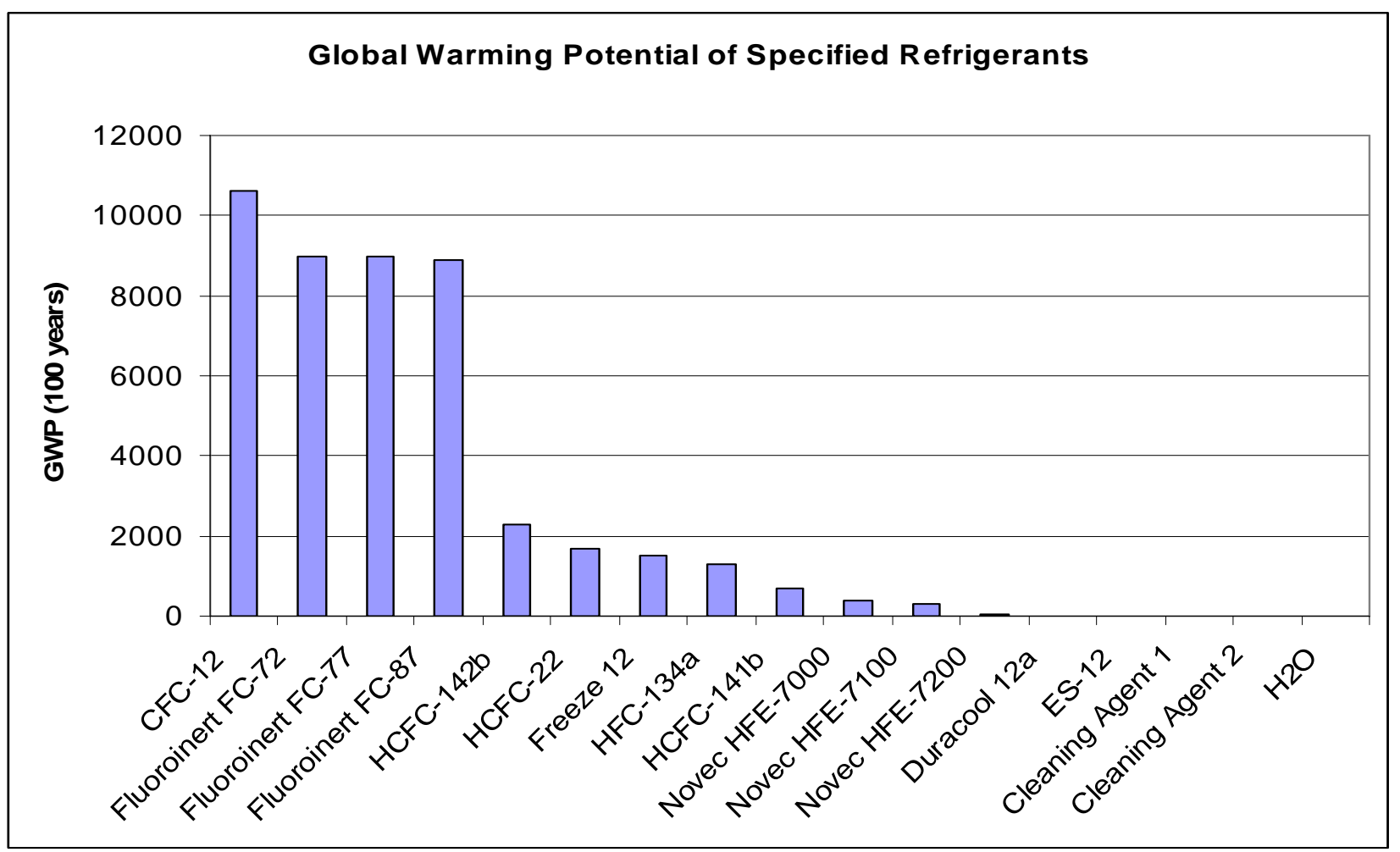

Fig. 2. Refrigerant GWP.

\section{TWO-PHASE COOLING}

Two thermo-physical properties important to two-phase cooling are latent heat and normal-boiling point. Figures 3 and 4 depict the latent-heat values of the refrigerants in reducing order. Figure 4 excludes water to demonstrate more clearly the relationship among the other refrigerants. These and other important physical properties of the refrigerants being examined are listed in Table 3. 


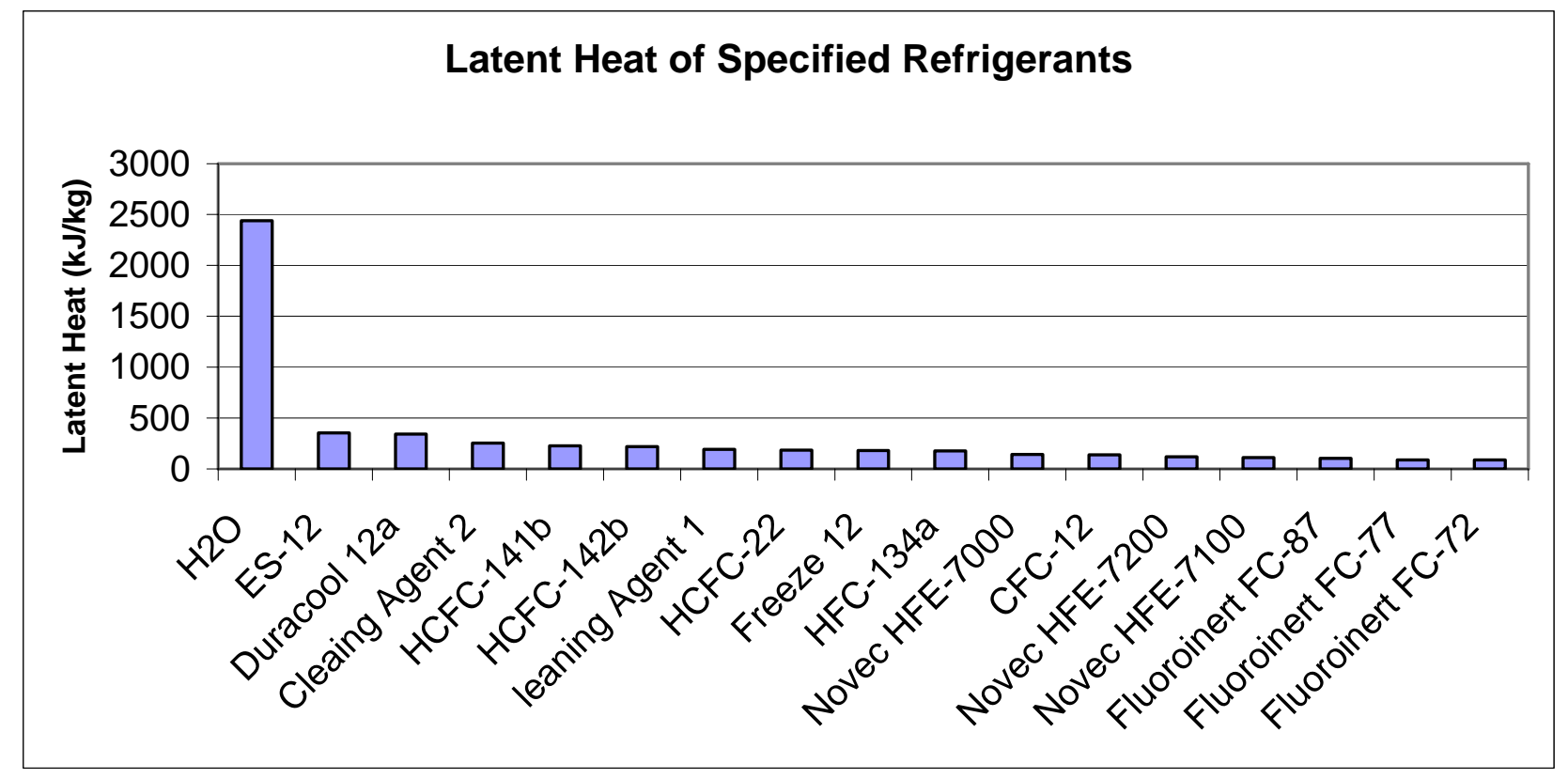

Fig. 3. Latent heat.

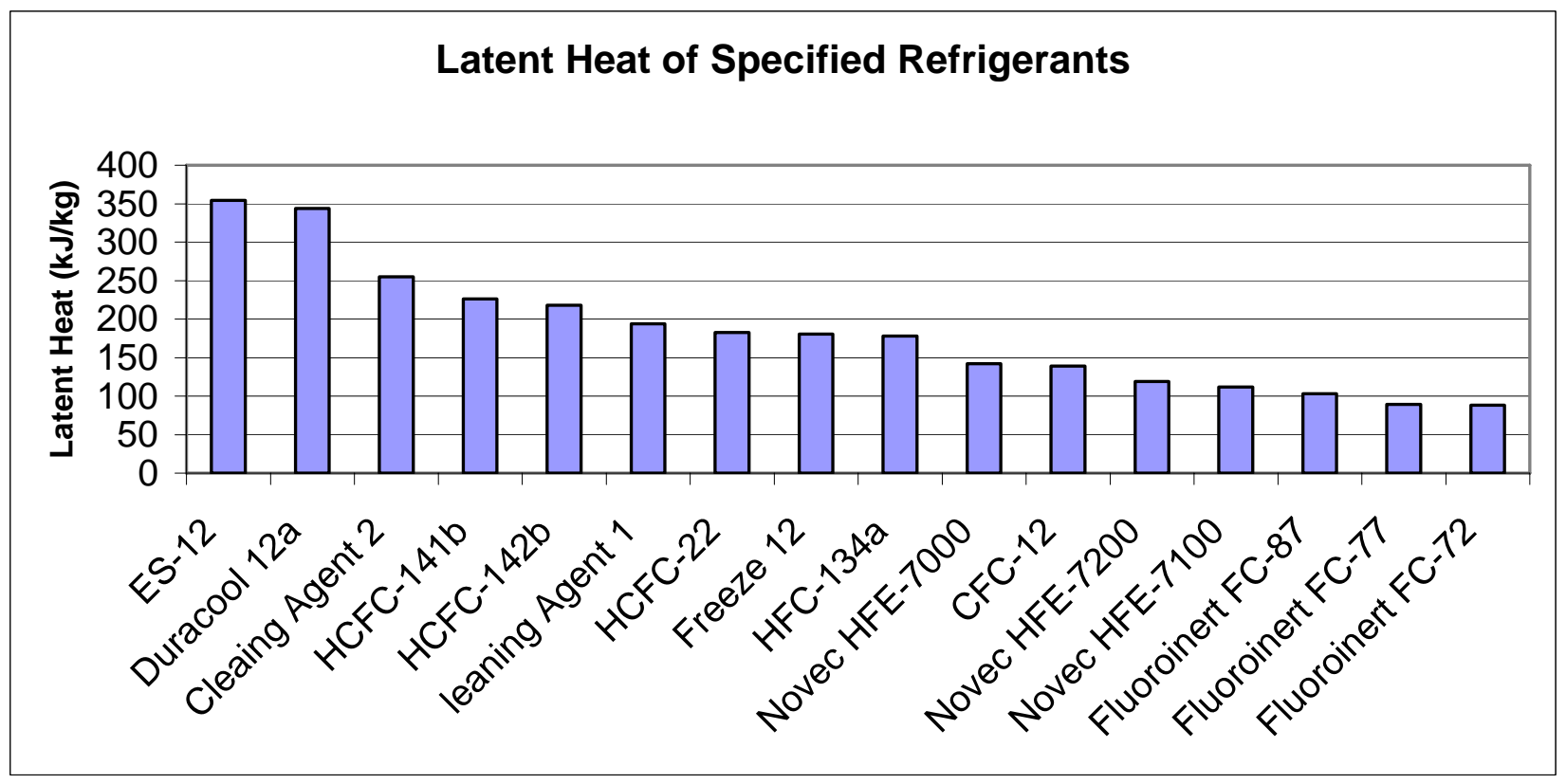

Fig. 4. Latent heat excluding water. 
Table 3. Physical properties

\begin{tabular}{|c|c|c|c|c|c|c|}
\hline Cooling fluid description & & & $\begin{array}{c}\text { Latent } \\
\text { heat @ } \\
25^{\circ} \mathrm{C}\end{array}$ & $\begin{array}{c}\text { Specific } \\
\text { heat } @ 25^{\circ} \mathrm{C}\end{array}$ & $\begin{array}{c}\text { Density @ } \\
\underline{25^{\circ} \mathrm{C}}\end{array}$ & $\begin{array}{c}\text { Normal } \\
\text { boiling } \\
\text { point }\end{array}$ \\
\hline & Company & Product name & $\mathrm{kJ} / \mathrm{kg}$ & $\begin{array}{l}\text { Liquid } \\
(\mathrm{KJ} / \mathrm{kg} / \mathrm{K})\end{array}$ & $\begin{array}{l}\text { liquid } \\
\mathrm{kg} / \mathrm{m}^{3}\end{array}$ & ${ }^{\circ} \mathrm{C}$ \\
\hline $1,1,1,2$ tetra fluorethane & Various & HFC-134a & 178 & 1.4 & 1210 & -26 \\
\hline 1,1-dichloro-1-fluoroethane & Various & HCFC-141b & 226 & 1.15 & 1234 & 32 \\
\hline 1-chloro-1,1-difluoroethane & various & HCFC-142b & 217.8 & 1.3 & 1.12 & -10 \\
\hline Dichlorodifluoro methane & Various & CFC-12 & 139 & 1 & 1311 & -29.8 \\
\hline Chlorodifluoro methane & Various & HCFC-22 & 182.7 & 1.26 & 1191 & -40.8 \\
\hline perfluorocarbon & $3 \mathrm{M}$ & Fluoroinert FC-87 & 103 & 1.1 & 1650 & 30 \\
\hline perfluorocarbon & $3 \mathrm{M}$ & Fluoroinert FC-72 & 88 & 1.1 & 1700 & 56 \\
\hline perfluorocarbon & $3 \mathrm{M}$ & Fluoroinert FC-77 & 89 & 1.1 & 1780 & 97 \\
\hline hydrofluoroether & $3 \mathrm{M}$ & Novec HFE-7000 & 142 & 1.3 & 1400 & 34 \\
\hline hydrofluoroether & $3 \mathrm{M}$ & Novec HFE-7100 & 112 & 1.17 & 1520 & 61 \\
\hline hydrofluoroether & $3 \mathrm{M}$ & Novec HFE-7200 & 119 & 1.22 & 1420 & 76 \\
\hline methylsiloxane & Dow Corning & Cleaing Agent 1 & 194 & 1.72 & 850 & 100 \\
\hline methylsiloxane $60 \%$ wlalcohol & Dow Corning & Cleaning Agent 2 & 255 & & 770 & 98 \\
\hline De-Ionized Water & & $\mathrm{H}_{2} \mathrm{O}$ & 2440 & 4.13 & 1002 & 100 \\
\hline $\begin{array}{c}\text { hydrocarbon blend } \\
\text { (butane/isobutane/propane) }\end{array}$ & Duracool & Duracool 12a & 343.5 & 2.56 & 526 & -31.5 \\
\hline $\begin{array}{c}\text { hydrocarbon blend } \\
\text { (propane/butane) }\end{array}$ & Enviro-safe & ES-12 & 354.2 & 2.574 & 530 & -30.4 \\
\hline $\begin{array}{c}\text { fluorocarbon blend } \\
\text { (HFC-134a/HCFC-142b) }\end{array}$ & $\begin{array}{l}\text { Technical } \\
\text { Chemical } \\
\end{array}$ & Freeze 12 & 180.7 & 1.4 & 1189 & -25 \\
\hline
\end{tabular}

From the observation of Fig. 3, water has the highest two-phase heat-transfer potential by

more than a factor of 6 . For this reason, water is often used in indirect cooling since the water does not come in contact with the electronics. Figure 4 reveals that the next highest refrigerants with the greatest two-phase heat-transfer potential are the HC blends. The lowest potential heattransfer refrigerants are HFE and PFC with latent-heat values smaller than $1 / 23$ that of water. 
In terms of the normal-boiling point, the refrigerants most suited for the task are those with boiling-point temperatures in the range $20-80^{\circ} \mathrm{C}$. From Table 3, these refrigerants include PFCs and HFE type refrigerants. HCFC, HFC, CFC, and HC refrigerants require a mediumpressure container to have both liquid and vapor phases due to the low values of the normalboiling points. The MS refrigerants have high normal-boiling point temperatures requiring a slightly subatmospheric pressure on the container. This gives PFC and HFE refrigerants an advantage in terms of safety, operation, and cost.

\section{DIELECTRIC STRENGTH}

Based on knowledge of the effects on the environment, latent heat, and normal-boiling point of refrigerants, the list of refrigerants was condensed as reflected on Table 4. CFC and PFC refrigerants were withdrawn from the list due to environmental concerns. Water, being a great conductor of electricity, is a poor dielectric and therefore unsuitable for direct cooling of PEs. Freeze 12 is a blend of two HC refrigerants already being tested and assumed to have similar characteristics in terms of dielectric strength. The last two refrigerants are untested and unproven technology for use as a refrigerant.

Since PEs can be cooled using two phases, both the liquid and vapor phases require dielectric-strength testing. The testing temperatures are based on the expected operating temperature of the two-phase mixtures. Saturated liquid and vapor denote the test pressure of the mixtures. To replicate the actual placement of PEs in the mixtures, sharp electrodes are used in the dielectric-strength test. 
Table 4. Dielectric strength table

\begin{tabular}{|c|c|c|c|}
\hline & & Dielectric Strength & Dielectric Strength \\
\hline & & Liquid (kV/mil) & Vapor (kV/mil) \\
\hline Products & Product Name & $50^{\circ} \mathrm{C} /$ Saturated Liquid & $50^{\circ} \mathrm{C} /$ Saturated Vapor \\
\hline \multirow[t]{2}{*}{$1,1,1,2$ tetra fluorethane } & HFC-134a & 7.2 & 6.7 \\
\hline & & $50{ }^{\circ} \mathrm{C} /$ Saturated Liquid & $50^{\circ} \mathrm{C} /$ Saturated Vapor \\
\hline \multirow[t]{2}{*}{\begin{tabular}{|l|} 
1-chloro-1,1- \\
difluoroethane \\
\end{tabular}} & HCFC-142b & 5.9 & 5.4 \\
\hline & & $50^{\circ} \mathrm{C} /$ Saturated Liquid & $50^{\circ} \mathrm{C} /$ Saturated Vapor \\
\hline \multirow[t]{2}{*}{$\begin{array}{l}1,1 \text { - dichloro -1- } \\
\text { fluoroethane }\end{array}$} & HCFC-141b & 6.1 & 4.4 \\
\hline & & $50^{\circ} \mathrm{C} /$ Saturated Liquid & $50^{\circ} \mathrm{C} /$ Saturated Vapor \\
\hline \multirow[t]{2}{*}{ hydrofluoroether } & Novec HFE-7000 & 8.0 & 6.0 \\
\hline & & $80{ }^{\circ} \mathrm{C} /$ Saturated Liquid & \\
\hline \multirow[t]{2}{*}{ hydrofluoroether } & Novec HFE-7100 & 8.1 & 7.1 \\
\hline & & $80^{\circ} \mathrm{C} /$ Saturated Liquid & $80^{\circ} \mathrm{C} /$ Saturated Vapor \\
\hline \multirow[t]{2}{*}{ hydrofluoroether } & Novec HFE-7200 & 7.7 & 3.8 \\
\hline & & $100^{\circ} \mathrm{C} /$ Saturated Liquid & $100^{\circ} \mathrm{C} /$ Saturated Vapor \\
\hline \multirow[t]{2}{*}{ methylsiloxane } & Cleaning Agent 1 & 7.6 & 5.4 \\
\hline & & $100^{\circ} \mathrm{C} /$ Saturated Liquid & $100^{\circ} \mathrm{C} /$ Saturated Vapor \\
\hline $\begin{array}{l}\text { methylsiloxane } 60 \% \\
\text { w/alcohol }\end{array}$ & Cleaning Agent 2 & 6.3 & 4.4 \\
\hline
\end{tabular}




\section{DISCUSSION OF TEST DATA}

Based on the results obtained from the dielectric-strength test and data collected concerning thermo-physical properties and the environmental effects of the different candidates, the MS refrigerants appear to have the most potential. The MS refrigerants have suitable dielectric strength, a large latent-heat value, and one of the lowest GWP. The only setback for MS refrigerants is flammability. The MS refrigerants are highly flammable and add risk in terms of cooling PEs. The normal-boiling point for these materials $\left(98-100^{\circ} \mathrm{C}\right)$ equates to a system pressure that is near atmospheric pressure. Since oxygen is required to cause ignition, these materials would need to be controlled to a slightly elevated pressure to keep oxygen out of the system.

Although the HC blends did not undergo the dielectric-strength test and are flammable like the MS refrigerants, HC blends show great thermal properties. The large latent-heat values and low GWP produced by HC blends shows that the HC blends have a great potential for use in refrigeration.

The HFC and HFE have the highest dielectric strength making these refrigerants applicable for PE cooling. Unlike the MS and HC blends, neither is flammable. HFC has a higher latent-heat value compared to that of HFE refrigerants providing better thermal transfer, but has a low normal-boiling point requiring a medium pressure container. HFEs have boiling points within the specified range of $20-80^{\circ} \mathrm{C}$ and therefore do not require a pressurized container. HFC refrigerants have a larger GWP compared to HFE by a factor of 3. Yet, HFC refrigerants are already in use in many vehicles and the cooling of PEs would not require an independent system from that of the air conditioner. 
Over the past two years, research at the Oak Ridge National Laboratory for direct cooling of control and PEs has been conducted using the HFC, which is R134a. Extensive testing and research with R134a has led to the development of a hybrid-drive component cooling system through the addition of a floating loop to the automobile air-conditioning unit. This floating loop uses R134a to cool the components of a hybrid vehicle without the use of an additional compressor enhancing the efficiency of the components and thereby the coefficient-ofperformance of the hybrid drive. The justification for the use of R134a has been that the refrigerant worked well with heat exchangers, has a good temperature range, and a great dielectric strength [7]. This study has also shown that the HFC refrigerant has low GWP ${ }^{*}$ and a moderate latent heat.

Although R134a has a low GWP*, the Kyoto Protocol signed in 1997 by 180 countries requires that 38 industrialized nations reduce their GWP emissions by $5.2 \%$ below levels seen in 1990 [8]. This reduction has made many nations seek alternatives to R134a, including most of Europe. Current research in Europe is directed towards R744, a carbon dioxide based refrigerant. However, R744 requires high pressure and cannot be used in existing automotive airconditioning systems [9].

\footnotetext{
* As seen in Table 2, other refrigerants such as CFC-12 and the PFCs, have a very high GWP; 9-10 times this number.
} 


\section{CONCLUSIONS}

HFC (R134-a) remains a good candidate for hybrid PE cooling with good mechanical properties, strong dielectric strength, non-flammability, and is already widely accepted in the auto industry.

HFE (Novec) fluids show good general properties for PE cooling, but are not presently used in automotive applications.

MS materials show excellent mechanical properties, but exhibit high flammability in conjunction with a high normal-boiling point at low system pressure and moderate dielectric strength. This creates the need for care in designing a safe oxygen-free system.

The HCFC materials show moderate to poor dielectric strengths and are slated to be removed from production in the near future due to significant ODP and GWP. 


\section{REFERENCES}

1. J. B. Campbell, L. M. Tolbert, C. W. Ayers, and B. Ozpineci, "Two-Phase Cooling Method Using R134a Refrigerant to Cool Power Electronic Devices,” pp. 141-147 in Applied Power Electronics Conference and Exposition, March 2005.

2. J. E. Wilkins, "Chlorofluorocarbons," pp. 78-80 in The Chapman \& Hall Encyclopedia of Environmental Science Kluwer Academic, Boston, Massachusetts, 1999.

3. K. V. Jog, Latest Trends in Air-Conditioning for Green Buildings, Green Building Congress, 2001.

4. The Montreal Protocol on Substances That Deplete the Ozone Layer, CIESIN Thematic Guides, 1996. "http://www.ciesin.org/TG/PI/POLICY/montpro.html”

5. The Challenge: Moving Away From HCFC Refrigerants, HRAI, The Heating, Refrigerating, and Air Conditioning Institute of Canada, 2005. "http://www.hrai.ca/hcfcphaseout/"

6. A. A. Ali, "Design and Analysis of a Compact Two Phase Cooling System for a Laptop Computer,” Thesis, Georgia Institute of Technology, June 2004.

7. K. T. Lowe, C. W. Ayers, and J. S. Hsu, Floating Refrigerant Loop Based on R-134a Refrigerant Cooling of High-Heat Flux Electronic, ORNL/TM-2005/223, UT-Battelle, LLC, Oak Ridge National Laboratory, October 2005.

8. What is the Kyoto Protocol, The Green Lane ${ }^{\mathrm{TM}}$, 2002. "http://www.ec.gc.ca/climate/kyotoe.html”

9. Valeo Develops Environmentally-Friendly R744 Air Condioning System, Industry Europe, Oct. 11，2005. " "http://www.industryeurope.net/servlet/processUserPage?action=show feature\&feature $=161 "$ 


\section{DISTRIBUTION}

\section{Internal}
1. D. J. Adams
2. C. W. Ayers
3. J. C. Conklin
4. E. C. Fox
5. K. P. Gambrell

\author{
6. J. S. Hsu \\ 7. L. D. Marlino \\ 8. M. Olszewski \\ 9. M. R. Starke \\ 10-11. Laboratory Records
}

\section{External}

12. T. Q. Duong, U.S. Department of Energy, EE-2G/Forrestal Building, 1000 Independence Avenue, S.W., Washington, D.C. 20585.

13. R. R. Fessler, BIZTEK Consulting, Inc., 820 Roslyn Place, Evanston, Illinois 60201-1724.

14. K. Fiegenschuh, Ford Motor Company, Scientific Research Laboratory, 2101 Village Road, MD-2247, Dearborn, Michigan 48121.

15. V. Garg, Ford Motor Company, 15050 Commerce Drive, North, Dearborn, Michigan 48120-1261.

16. E. Jih, Ford Motor Company, Scientific Research Laboratory, 2101 Village Road, MD1170, Rm. 2331, Dearborn, Michigan 48121.

17. A. Lee, Daimler Chrysler, CIMS 484-08-06, 800 Chrysler Drive, Auburn Hills, Michigan $48326-2757$.

18. F. Liang, Ford Motor Company, Scientific Research Laboratory, 2101 Village Road, MD1170, Rm. 2331/SRL, Dearborn, Michigan 48121.

19. M. W. Lloyd, Energetics, Inc., 7164 Columbia Gateway Drive, Columbia, Maryland 21046.

20. Brenda Medellon, USCAR, brenda@uscar.org

21. M. Mehall, Ford Motor Company, Scientific Research Laboratory, 2101 Village Road, MD-2247, Rm. 3317, Dearborn, Michigan 48124-2053.

22. J. Rogers, Chemical and Environmental Sciences Laboratory, GM R\&D Center, 30500 Mound Road, Warren, Michigan 48090-9055.

23. S. A. Rogers, U.S. Department of Energy, EE-2G/Forrestal Building, 1000 Independence Avenue, S.W., Washington, D.C. 20585.

24. G. S. Smith, General Motors Advanced Technology Center, 3050 Lomita Boulevard, Torrance, California 90505.

25. E. J. Wall, U.S. Department of Energy, EE-2G/Forrestal Building, 1000 Independence Avenue, S.W., Washington, D.C. 20585.

26. B. Welchko, General Motors Advanced Technology Center, 3050 Lomita Boulevard, Torrance, California 90505.

27. P. G. Yoshida, U.S. Department of Energy, EE-2G/Forrestal Building, 1000 Independence Avenue, S.W., Washington, D.C. 20585. 